\title{
Response competition in conditioned avoidance
}

\author{
J. T. GREENE AND L. J. PEACOCK \\ UNIVERSITY OF GEORGIA
}

\begin{abstract}
Abstraet
An ultrasonic activity recording device was used to permit a rat to avoid shock by moving about 1 in in any direction. Groups of 10 Ss were used with CS-UCS intervals of 5 and $15 \mathrm{sec}$. Only three of the $20 \mathrm{Ss}$ learned to avoid shock by movement. The results are discussed in terms of the analysis of avoidance learning put forth by Meyer, Cho, \& Weseman (1960); it is suggested that their hypothesis needs some revision to account for the present results.
\end{abstract}

\section{Introduction}

In research on learning in lower animals, avoidance conditioning has been used extensively with a wide range of independent variables. However, it has become increasingly apparent that the technique is not as straightforward a learning process as earlier studies had indicated. Meyer et al (1960), for example, found that discriminated lever press avoidance responses sometimes were not established in rats after 10 or $20 \mathrm{hr}$. of training.

Their explanation of this and similar failures by other investigators is based on the concept of response topography and on Schoenfeld's (1950) analysis of the avoidance situation. They hypothesize that the nature of the response required to avoid shock must be antagonistic to, i.e., incompatible with, the freezing-crouching response pattern often observed when a naive animal is electrodermally stimulated. Lever pressing behavior, then, might not be easily learned since its topography can be compatible with the freezing-crouching behavior.

In suggesting behavior which should be easily learned, Meyer stated "the situation is different with a jump or running response; these yield us competition, termination-and rapid avoidance learning"' (Meyer, 1960, p. 227)。

According to this line of reasoning, locomotor responses by the animal should be most easily learned; and success of the shuttleboxas a technique of avoidance learning supports such a view. In the shuttlebox, however, the rat must run or jump somewhere. That is, the animal's locomotor response is directed by the environment. Is the important consideration in rapid avoidance learning the fact of running or jumping or is it a relatively specific change of location of the animal? As Meyer's hypothesis is stated, it would be logical to assume that movement in and of itself, as a response, without the animal's behavior being directed by the apparatus, would result in rapid avoidance learning. The present experiment was intended to test this extension of Meyer's (1960) hypothesis by making the required response "non-directed" movement: movement in any direction, by any part of the animal's body, or by the entire animal, to an extent of 1 in or more.

\author{
Method \\ Subjects \\ Ss were 30 male Sprague-Dawley rats 95-140 days \\ old. \\ Apparatus
}

The Ss' experimental environment was a white wooden box 21.2 by 20.2 by $22.3 \mathrm{~cm}$ with a grid floor and a sliding glass ceiling. The onset of a light illuminating the interior of the box was the conditional stimulus. Illumination level in the box without the CS was $2 \mathrm{ft}-$ candles, and with the CS on it was $14 \mathrm{ft}$-candles. Set flush in one end of the box were two transducers of an ultrasonic activity recording device (Peacock \& Williams, 1962). From the readout unit of this apparatus eletrical impulses were conducted to a cumulative recorder and to an electronic timer. The timer turned on the CS after a preset interval of no recorded activity. Upon onset of the CS, the cycle of a second timer was begun. Upon completion of this second cycle, the UCS (shock to the S's feet through the grid floor) was introduced by an Applegate stimulator. The amount of current through the grids was .35 to $.45 \mathrm{ma}$. An electromechanical scrambling device alternated polarity of current through the grids so that the animal could not escape shock by remaining on bars of the same polarity.

Units of the S's activity and the number and duration of shocks were recorded on the cumulative recorder. All apparatus was automatically controlled, with the relay and scrambling mechanisms being located outside the experimental room. White noise was delivered through a speaker to the experimental room, in which illumination was kept as low as possible consistent with visual observation of the $\mathrm{S}$ by means of an overhead mirror.

Procedure

Ss were handled for 14 days prior to their experimental trials. On the last five of these days they were also placed in the box for $30 \mathrm{~min}$. with all experimental conditions present except the CS and the UCS. Ss were handled $5 \mathrm{~min}$. before and after all sessions. Experimental sessions were of $2 \mathrm{hr}$. duration; four sessions were conducted daily at fixed hours. The experimental trials totaled $10 \mathrm{hr}$. for all $\mathrm{Ss}$, one session daily for five consecutive days. Ss were randomly assigned to one of three groups, $10 \mathrm{Ss}$ per group. Groups were staggered with respect to the time of day of the session. Presentation of the stimuli were as follows: Experimental Group I

After 5 sec. of no recorded movement, the CS was presented. If movement was recorded within $15 \mathrm{sec}$. after CS onset, another sequence was begun. If the $\mathrm{S}$ failed to move within $15 \mathrm{sec}$. after CS onset, the grid 
TABLE I

MEAN HOURLY ACTIVITY OF EXPERIMENTAL AND CONTROL GROUPS

\begin{tabular}{|c|c|c|c|}
\hline & E I & E II & C \\
\hline \multicolumn{4}{|c|}{ Hour } \\
\hline 1 & 215.16 & 204.24 & 210.30 \\
\hline 2 & 195.36 & 203.16 & 179.28 \\
\hline 3 & 208.20 & 185.04 & 204.00 \\
\hline 4 & 203.04 & 195.36 & 121.80 \\
\hline 5 & 195.96 & 170.52 & 156.00 \\
\hline 6 & 189.84 & 170.04 & 106.86 \\
\hline 7 & 186.36 & 169.80 & 193.80 \\
\hline 8 & 163.32 & 178.44 & 147.66 \\
\hline 9 & 165.12 & 167.28 & 136.20 \\
\hline 10 & 145.56 & 186.72 & 80.40 \\
\hline
\end{tabular}

was charged, shock and light being simultaneously terminated when movement occurred.

Experimental Group II

This group was identical to E I except that the CS-UCS interval was $5 \mathrm{sec}$.

Control Group

After $5 \mathrm{sec}$. of no recorded movement, the CS was presented. The CS was terminated when movement was recorded. These control Ss were never shocked.

The amount of movement sufficient to be recorded as one unit of activity (the minimum necessary to activate relay mechanisms to delay shock) was about 1 in in any direction. Total activity for each minute was measured in these units. The number of shocks received and the total activity were recorded for each consecutive 5 min. period.

\section{Result:}

Neither experimental group reduced significantly the number of shocks received. The mean amount of activity was significantly higher in the experimental groups than in the control group (Table 1). The control group exhibited a significant decrease in activity from the first to the last session, as well as a significant difference between the first and second hours of each session. The variability of the control Ss was considerably larger $(\mathrm{SD}=42.8)$ than that of the experimental animals $(\mathrm{SD}=12.7)$.

\section{Disenssion}

According to our interpretation of Meyer's hypothesis, the experimental Ss in this study should have learned an avoidance response easily within the time limits used. Of several possible reasons for the absence of learning, one which seems likely is in the amount of response freedom allowed. Since any movement of 1 in or more in any direction served to postpone shock, no specific movement was exclusively reinforced. It appears from our data that some degree of response specificity is necessary for successful avoidance learning. Response specificity is usually forced upon a $\mathrm{S}$ by the apparatus: a lever must be pushed, a hurdle jumped, a pole climbed. The ultrasonic device, however, permits movement qua movement to serve as a response, and response specificity is not in any known way shaped by the apparatus.

Visual observation of the three experimental Ss which reached the learning criterion revealed considerable response specificity. One $\mathrm{S}$, for example, showed a stereotyped head-turning. It is possible that this rat's behavior was shaped by accidental, successive reinforcement of the head-turning enough times for it to be established.

\section{Conelusions}

The results of this study suggest that Meyer's hypothesis as stated requires some revision. Response antagonism of freezing-crouching behavior by bodily movements of 1 in or more does not appear to be sufficient for rapid avoidance learning to occur. Some degree of response specificity or selective reinforcement appears to be needed in addition.

\section{Referemees}

Meyer, D. R., Cho, C., \& Weseman, A. F. On problems of conditioning discriminated lever-press avoidance. Psychol. Rev., 1960, 67, 224-228.

Schoenfeld, W. N. An experimental approach to anxiety, escape and avoidance behavior. In P. J. Hoch and J. Zubin (Eds.), Anxiety. New York: Grune \& Stratton, 1950.

Peacock, L. J., \& Williams, M. An ultrasonic device for recording activity. Amer. J. Psychol., 1962, 75, 648-652. 